SATIN - Sains dan Teknologi Informasi

\title{
Sistem Informasi Penilaian Kinerja Karyawan Pada Yayasan Kasih Suwitno Berbasis Web
}

\author{
Rosadi \\ STMIK Nusa Mandiri \\ Rosadi2309@gmail.com
}

\author{
Ghofar Taufik \\ Universitas Bina Sarana Informatika \\ Ghofar.gft@nusamandiri.ac.id
}

\begin{abstract}
Performance appraisal system is important in the company, in understanding the development of company performance. Performance appraisal is done manually. This was also experienced by the Yayasan Kasih Suwitno, where employee appraisals still use manual methods. Staff who will provide reports to supervisors and submit assessment results to superiors who are then corrected and added by superiors, still use paper. This causes data transmission and tends to reproduce because it must be written and calculated manually. In addition, the results of employee assessments cannot be seen every period. With the web-based performance appraisal system, which was developed with the Waterfall system development model and the PHP (Hipertext Prepocessor) programming language, estimates and delivery of data results will be faster sent to the supervisor or to the central party. In addition, performance developments can be seen in each period.
\end{abstract}

Keywords: Performance, Employees, Assessment, Supervisor.

\begin{abstract}
Abstrak
Sistem penilaian kinerja karyawan merupakan hal penting dalam sebuah perusahaan, dalam mengetahui perkembangan kinerja karyawan perusahaan. Penilaian kinerja yang dilakukan secara manual menjadi permasalahan tersendiri bagi sebuah perusahaan. Hal ini juga dialami Yayasan Kasih Suwitno, dimana penilaian kinerja karyawan masih menggunakan cara manual. Staf yang akan melakukan
\end{abstract}

penilaian kepada rekan sejawat dan menyerahkan hasil penilaian ke supervisor yang kemudian dikoreksi dan ditambahkan penilaian oleh supervisor, masih menggunakan kertas. Hal ini menyebabkan pengiriman data dan penilaian menjadi lebih merepotkan karena harus di tulis dan dihitung secara manual. Selain itu, hasil penilaian karyawan tidak dapat dilihat setiap periodenya. Dengan adanya sistem penilaian kinerja karyawan berbasis web, yang dikembangkan dengan model pengembangan sistem Waterfall dan bahasa pemerograman PHP (Hipertext Prepocessor), maka penilaian dan pengiriman data hasil penilaian akan lebih cepat dikirim ke supervisor maupun ke pihak pusat. Selain itu juga perkembangan kinerja karyawan dapat dilihat dalam tiap periode.

Kata Kunci : Kinerja, Karyawan, Penilaian, Supervisor.

\section{Pendahuluan}

Penilaian kinerja merupakan bagian dari kegiatan perusahaan dalam mengevaluasi perilaku prestasi kerja pegawai serta menetapkan kebijakan untuk jenjang karir karyawan selanjutnya. Hal itu menjadi masalah penting bagi seluruh organisasi atau perusahaan, untuk mendapatkan hasil kinerja karyawan yang memuaskan. Tentu bukan hal yang terjadi begitu saja, para pegawai atau karyawan harus melalui proses evaluasi untuk menilai kinerja mereka. Kinerja karyawan merupakan suatu kondisi yang harus diketahui dan dikonfirmasikan kepada pihak tertentu untuk mengetahui tingkat pencapaian hasil seorang 
pegawai yang berhubungan dengan visi dan misi yang dimiliki suatu organisasi atau perusahaan.

Dalam proses kegiatan penilaian setiap periode, yaitu antara bulan Januari sampai Desember setiap tahunnya, Yayasan kasih suwitno melakukan penilaian dengan menggunakan form dalam bentuk kertas. Dimana, staff mengisi penilaian yang di berikan untuk rekan satu divisi. Setelah melakukan pengisian penilaian, tahap selanjutnya hasil penilaian diserahkan ke supervisor atau atasan dalam satu divisi. Setelah itu, supervisor melakukan penilaian tersendiri. Setelah selesai melakukan penilaian, kemudian supervisor betemu dan melakukan tatap muka dengan staff yang melakukan penilaian dan mendiskusikan atas penilaian yang di berikan oleh staff dan supervisor. Apabila supervisor tidak setuju atas penilaian yang di berikan oleh staff, maka nilai akan di revisi atau di perbaiki.

Menurut Safitri \& Waruwu (2017), menyimpulkan bahwa :

Karyawan merupakan salah satu sumber daya yang di gunakan sebagai alat penggerak dalam memajukan suatu perusahaan. Kinerja karyawan cukup berpengaruh dalam keuntungan yang didapat oleh perusahaan tersebut. Untuk memacu kinerja karyawan, maka suatu perusahaan melakukan pemilihan karyawan berprestasi setiap priodenya dengan memberikan bonus atau kenaikan gaji pada setiap karyawan yang terpilih.

Tingkat persaingan kerja yang semakin besar mendorong karyawan untuk lebih meningkatkan kinerjanya dan memberikan kinerja yang terbaik.Hampir semua karyawan mendambakan untuk mendapatkan karier diperusahan yang dia bekerja karena pada dasarnya karyawan menginginkan kehidupan yang lebih baik dari sebelumnya seperti pendapatan yang lebih tinggi, bonus dan fasilitas yang diberikan oleh perusahaan. Andini \& Arif (2017).

Setiap perusahaan tentunya mempunyai standar penilaian masing-masing, baik dari bobot nilai yang diberikan, perhitungan nilai, periode penilaian, hasil akhir penilaian, sistem penilaian maupun dari cara melakukan penilaian. Ada perusahaan yang sudah menerapkan sistem penilaian secara online atau terkomputerisasi, bahkan ada pula yang sistemnya masih manual.

Pada yayasan kasih suwitno, penilaian kinerja karyawan bertujuan untuk pertimbangan supervisor untuk mempertahankan kontrak kerja atau promosi jabatan. Adapun kriteria umum dalam penilaian tersebut adalah sebagai berikut :

1. Understanding of the requirements of the project and the Employee's Terms of Reference (Mengerti akan kebutuhan program dan Kerangka Acuan karyawan)

2. Awareness and response to risks, issues and problems associated with the Terms of Reference (Mengerti dan menanggapi risiko, masalah, masalah dan permasalaha yang terkait dengan Kerangka Acuan)

3. Effectiveness of communications with colleagues, supervisor, counterparts, and other stakeholders (efektif dalam berkomunikasi dengan rekan kerja, supervisor, Counterpart, pemegang saham )

4. Responsiveness to requests and Instructions (Sangat respond terhadap permintaan dan instruksi)

5. Quality of work / performance /achievement \& deliverables (including reports, assessments \& advice) (Kwalitas kerja/penilaian dan pencapaian dan Tanggung Jawab (termasuk laporan, penilaian dan saran)

Dengan rating penilaian 1-6

Tabel 1. Rating dan Kriteria penilaian.

\begin{tabular}{|c|c|c|}
\hline$>=1-<=2$ & $\begin{array}{l}\text { Very } \\
\text { Weak } \\
\text { Sangat } \\
\text { lemah }\end{array}$ & 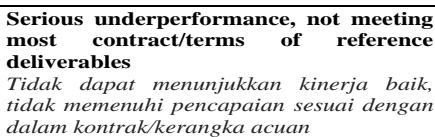 \\
\hline$>2-<=3$ & $\begin{array}{l}\text { Weak } \\
\text { Lemah }\end{array}$ & $\begin{array}{l}\text { Major effort needed to improve delivery } \\
\text { of core responsibilities identified in the } \\
\text { contract/terms of reference } \\
\text { Membutuhkan upaya besar untuk } \\
\text { meningkatkan penyelesaian tanggung } \\
\text { jawab terbesaryang sudah didentifikasikan } \\
\text { dalam kontrak/kerangka acuan }\end{array}$ \\
\hline$>3-<=4$ & $\begin{array}{l}\text { Less than } \\
\text { satisfactor } \\
\boldsymbol{y} \\
\text { Kurang } \\
\text { dari } \\
\text { memuaska } \\
n\end{array}$ & $\begin{array}{l}\text { Effort needed to improve delivery of one } \\
\text { or more core responsibilities identified in } \\
\text { the contract/terms of reference } \\
\text { Memerlukan upaya untuk meningkatkan } \\
\text { pencapaian satu atau lebih tanggung Jawab } \\
\text { yang sudah diidentifikasikan dalam } \\
\text { kontrak/kerangka acuan }\end{array}$ \\
\hline$>4-<=5$ & $\begin{array}{l}\text { Satisfacto } \\
\boldsymbol{r y} \\
\text { Memuask } \\
\text { an }\end{array}$ & $\begin{array}{l}\text { Minor effort needed to improve delivery } \\
\text { of some areas of responsibility identified } \\
\text { in the contract/terms of reference } \\
\text { Membutuhkan sedikit upaya untuk } \\
\text { meningkatkan pencapaian tanggung jawab } \\
\text { dalam beberapa hal yang tercantum dalam } \\
\text { kontrak/kerangka acuan }\end{array}$ \\
\hline$>5-<=6$ & $\begin{array}{l}\text { Very } \\
\text { Good } \\
\text { Sangat } \\
\text { baik }\end{array}$ & $\begin{array}{l}\text { All responsibilities identified in the } \\
\text { contract/terms of reference delivered } \\
\text { efficiently and effectively } \\
\text { Semua tanggung jawab yang sudah } \\
\text { disetujui dalam kontrak / kerangka acuan } \\
\text { sudah dicapai secara efisien dan efektif }\end{array}$ \\
\hline$<6$ & $\begin{array}{l}\text { Outstandi } \\
\text { ng } \\
\text { Melebihi } \\
\text { dari yang } \\
\text { diharapka } \\
n\end{array}$ & $\begin{array}{l}\text { All responsibilities identified in the } \\
\text { contract/terms of reference delivered } \\
\text { with a high degree of efficiency and } \\
\text { effectiveness, efficiently, and proactive } \\
\text { steps taken to achieve outcomes above } \\
\text { and beyond identified responsibilities } \\
\text { Semua tanggung jawab persetujuan dalam } \\
\text { kontrak / kerangka acuan dicapai secara } \\
\text { efisien dan efektif dengan tingkatan yang } \\
\text { tinggi dan langkah-langkah proaktifdiambil } \\
\text { untuk mencapai mencapai hasil diatas dan } \\
\text { di luar tanggung Jawab yang sudah } \\
\text { disetujui }\end{array}$ \\
\hline
\end{tabular}

\section{Landasan Teori}

\subsection{Konsep Dasar Sistem}

Menurut A.S \& M.salahuddin (2018:2), Menjelaskan bahwa "Sistem perangkat lunak berati sebuah sistem yang memiliki komponen berupa perangkat lunak yang memiliki hubungan satu sama lain untuk memenuhi kebutuhan pelanggan (customer)."

Sistem informasi merupakan sekumpulan komponen pembentuk sistem yang mempunyai keterkaitan antara satu komponen dengan komponen 
lainnya yang bertujuan menghasilkan suatu informasi dalam suatu bidang tertentu. Magai et al. (2018).

\subsection{Rekayasa perangkat Lunak}

Rekayasa Perangkat Lunak Perangkat lunak (software) adalah programkomputer yang terasosiasi dengan dokumentasi perangkat lunak seperti dokumentasi kebutuhan, model desain, dan cara penggunaan (user manual). Sebuah program komputer tanpa terasosiasi dengan dokumentasinya maka belum dapat disebut perangkat lunak (software). Sebuah perangkat lunak juga sering disebut dengan sistem perangkat lunak. Sistem berarti kumpulan komponen yang saling terkait dan mempunyai satu tujuan yang ingin dicapai (Aldo \& Informasi, 2019)

\subsection{Perancangan Sistem}

Menurut Munawar (2018:26), Menjelaskan bahwa Secara umum perancangan sistem terbagi menjadi dua bagian yaitu perancangan sistem dan perancangan detil. Perancangan sistem terkait dengan keseluruhan arsitektur sistem dan penetapan standard yang akan dipakai saat implementasi. Sementara perancangan detil terkait dengan perancangan masing-masing komponen agar sesuai dengan arsitektur sistem dan standard yang di gunakan.

\subsection{Kinerja Karyawan}

Menurut Mangkuprawira dan Vitalaya dalam Agung et al. (2016), Penilaian kinerja adalah salah satu tugas penting untuk dilakukan oleh seorang manajer atau pimpinan karena dapat digunakan untuk memperbaiki keputusan-keputusan personalia dan memberikan umpan balik kepada pegawai tentang kinerja pegawai tersebut

Menurut Hamali (2018:98), "Kinerja merupakan hasil pekerjaan yang mempunyai hubungan kuat dengan strategis organisasi, kepuasan konsumen, dan memberikan kontribusi pada ekonomi”.

Menurut Magai et al. (2018) Menyimpulkan bahwa : "Kinerja merupakan hasil yang diperoleh oleh suatu organisasi baik organisasi tersebut bersifat profit oriented dan non profit oriented yang dihasilkan selama satu periode waktu, dan kualitas dari kinerja pegawai tidak terlepas dari pencapaian hasil kerja".

Tujuan dilakukan penilaian kinerja adalah untuk mengetahui perkembangan terkait dengan pekerjaan pegawai apakah mengalami kenaikan atau penurunan. Kurniawan et al. (2016).

\subsection{Web Server}

Menaurut winarno sugeng dalam (Efrando, 2019) Web server adalah sebuah perangkat lunak server yang berfungsi menerima permintaan HTTP atau HTTPS dari klien yang dikenal dengan web browser dan mengirimakan kembali hasilnya dalam bentuk halaman-halaman web yang umumnya berbentuk dokumen HTML. Server web yang terkenal diantaranya adalah Apache dan Microsoft Internet Information Service (ISS).Web server menunggu permintaan dari client yang menggunakan browser seperti Internet Explorer, Mozilla Firefox, Opera, dan program browser lainnya.

\section{Metodologi Penelitian}

\subsection{Metode Pengumpulan Data}

Metode penelitian yang digunakan pada penelitian ini adalah metode deskriptif, yaitu penelitian yang dilakukan berdasarkan keadaan yang sebenarnya dengan membandingkan teori kemudian mengambil kesimpulan. Adapun metode pengumpulan data yang dilakukan pada penelitian ini adalah sebagai berikut:

\section{Observasi}

Pada tahap ini Penulis melakukan pengamatan langsung ke Yayasan Kasih Suwitno yang berada di Jl. Guntur raya No.44 RT/RW 01/01, Kel. Guntur, Kec. Setiabudi, Jakarta Selatan.

\section{Wawancara}

Metode yang di lakukan adalah dengan cara tanya jawab dan menggali informasi secara langsung dengan HRD Yayasan kasih suwitno untuk mendapatkan data yang lengkap dan akurat.

\section{Studi Pustaka}

Penulis mencari referensi dan pengumpulan data dengan membaca jurnal, artikel dari berbagai situs internet, seperti e-book, e-journal, serta buku-buku yang mendukung dengan tema yang di angkat dan berhubungan dengan sistem yang akan di bangun yaitu sistem online.

\subsection{Tahapan Penelitian}

\section{Analisa Kebutuhan Sistem}

Aplikasi yang akan di bangun meliputi tiga bagian utama, yaitu halaman admin (panel administrator) dan halaman user yang terdiri dari halaman supervisor dan halaman staff penilai. Masing- masing halaman ini memiliki fungsi yang berbeda, halaman admin di gunakan untuk memasukan dan memanipulasi datadata master, seperti data staff yang akan melakukan penilaian, karyawan atau staff yang akan di nilai, supervisor dan lokasi kantor apabila terjadi penambahan kantor cabang baru. Halaman staff penilai di gunakan untuk menilai staff lain dan memberikan masukan atau catatan untuk staff lain yang akan di nilai. Dan halaman supervisor, digunakan untuk memvalidasi hasil penilaian yang di lakukan oleh staff penilai sebelum di serahkan ke pimpinan pusat.

\section{Desain}


Merancang gambaran sistem dengan menggunakan perangkat permodelan sistem UML ( Unified Modeling Language), LRS (Logical Record Structure), dan hubungan diagram entitas ERD (Entity Relationship Diagram).

\section{Code Generation}

Bahasa yang di gunakan dalam pembuatan website sistem penilaian kinerja karyawan pada yayasan kasih suwitno adalah bahasa pemerograman berbasis object yaitu $p h p$, css dan jquery. Dalam proses pembuatannya bahasa pemerograman yang di gunakan yaitu PHP dan database MySql .

\section{Testing}

Dalam pembuatan website ini nantinya akan dilakukan pengujian (testing) dengan menggunakan metode blackbox testing yang di lakukan setelah website sistem penilaian kinerja ini dibuat. Tujuannya adalah untuk mengetahui apakah sistem sudah sesuai dengan yang di harapkan atau belum, jika belum sesuai maka akan dilakukan penyesuaian ulang.

\section{Support}

Upaya yang di lakukan dalam pengembangan sistem yang di buat yaitu :

a. Menentukan ide yang di perlukan dalam pembuatan website sistem penilaian kinerja karyawan.

b. Merincikan apa saja kebutuhan yang di perlukan dalam pengembangan web agar mudah di gunakan.

c. Website sistem penilaian kinerja karyawan ini dibuat dengan software Adobe Dreamweaver CS5.5 dan database PHP MySql dari XAMPP dengan sistem operation windows 10 dan hardware yang didukung dengan processor AMD A8-6410 APU with AMD Radeon R5 Graphics $2.0 \mathrm{GHz}$.

\section{MODEL PENGEMBANGAN SISTEM}

Pada pengembangan sistem ini, penulis menggunkan model waterfall (air terjun) yang mengacu pada ilmu rekayasa perangkat lunak, yaitu sebagai berikut.

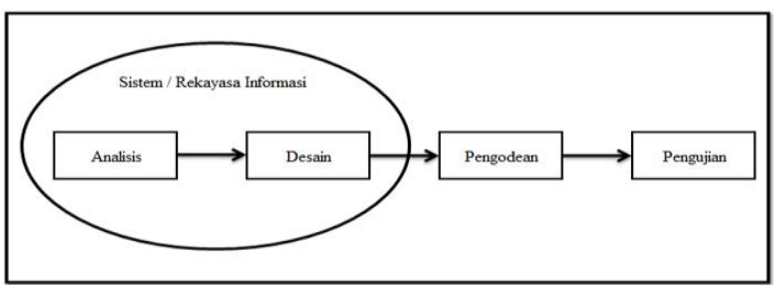

Gambar 1. Model Waterfall

Sumber : Rosa dan Shalahuddin (2018:29)
Menurut A.S \& M.salahuddin (2018:28), Model SDLC air terjun (waterfall) sering juga di sebut model sekuensial linier (sequential linear) atau alur hidup klasik (clasic life cycle). Model air terjun menyediakan pendekatan alur hidup perangkat lunak secara sekuensial atau terurut dimulai dari analisis, desain, pengodean, pengujian, dan tahap pendukung (support).

\section{Hasil dan Pembahasan}

Dengan dibentuknya sistem ini, dihrapkan dapat menjadikan sistem yang semula tradisional dapat bisa diakses secara cepat. Sistem yang diusulkan merupakan sistem yang sebelumnya sudah ada, kemudian dirancang menjadi sistem berbasis online menggunakan jaringan intranet.

Adapun hasil rancangan yang diperoleh berisikan tampilan dari prgram yang meliputi rekap data, penginputan data master, penilaian dan laporan.

\subsection{Tahapan Analisa}

Dalam menganalisa sebuah sistem, terdapat beberapa langkah yang harus dilakukan. Langkah atau prosedur analisa sistem, hampir sama halnya dengan mendefinisikan proyek-proyek yang akan di kembangkan pada tahap perencanaan sistem, bedanya hanya di ruang lingkup tugasnya.

Perancangan sistem penilaian kinerja karyawan pada Yayasan Kasih Suwitno adalah dengan staff dan supervisor dapat mengakses sistem secara online melalui intranet dikantor. Staff yang akan melakukan penilaian mengakses sistem penilaian kinerja karyawan yang di akses dengan menyambungkan komputer ke jaringan intranet kantor dan membukanya melalui web browser. Begitu juga dengan supervisor yang akan melakukan penilaian, harus menyambungkan ke jaringan intranet yang telah disediakan di kantor, agar dapat mengakses sistem penilaian kinerja karyawan. Berikut ini adalah spesifikasi sistem kebutuhan (system requirement) atau kemampuan dari program aplikasi Penilaian kinerja karyawan yang akan di bangun.

\section{Use Case Diagram}

Perancangan use case akan menampilkan bagaimana seseorang (aktor) memanfaatkan sistem atau menggunakan sistem yang ada. aktor berhubungan langsung dengan use case.

Adapun yang bertindak sebagai aktor pada website ini adalah admnistrator, Staff Penilai dan Supervisior. 


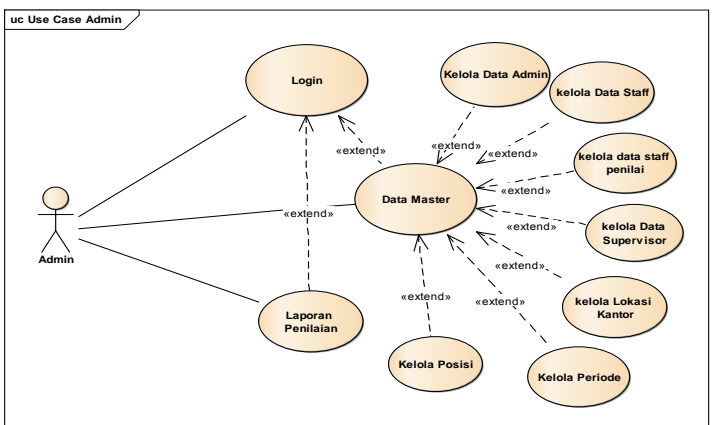

Gambar 2. Usecase Diagram Halaman Administrator

Pada halaman ini, administrator dapat mengelola data, Administrator lain, Mengelola data staff, mengelola data staff penilai, mengelola data supervisor penilai, mengelola data posisi staff, mengelola data lokasi kantor, mengelola periode penilaian,melihat laporan penilaian.

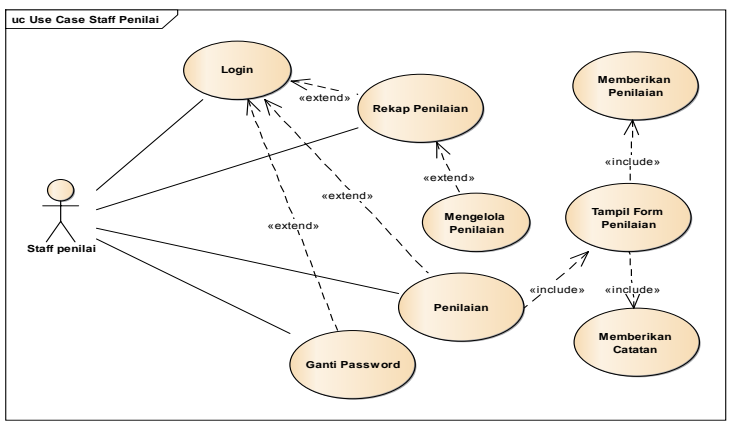

Gambar 3. Usecase Diagram Halaman Staff penilai

Staff penilai dapat melakukan login ke sistem penilaian kinerja karyawan, dapat mengelola penilaian, dapat melihat rekap penilaian, dapat mengganti password.

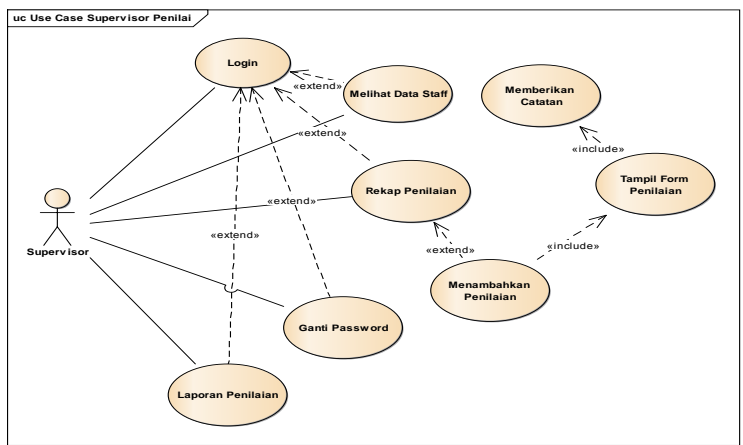

Gambar 4. Usecase Diagram Halaman Supervisor

Supervisor dapat melakukan login ke sistem penilaian kinerja karyawan, melihat data staff, melihat rekap penilaian \& Mengelola Penilaian, melihat laporan penilaian,mengganti password untuk login akun .

\section{Activity Diagram}

Activity Diagram atau diagram aktivitas merupakan gambaran aliran kerja atau aktivitas dari sebuah sistem atau proses bisnis yang terdapat pada aplikasi perangkat lunak. Activity diagram menggambarkan aktivitas sistem yang di lakukan actor.

a. Activity Diagram Halaman Administrator.

\section{Activity Diagram Kelola Data Administrator}

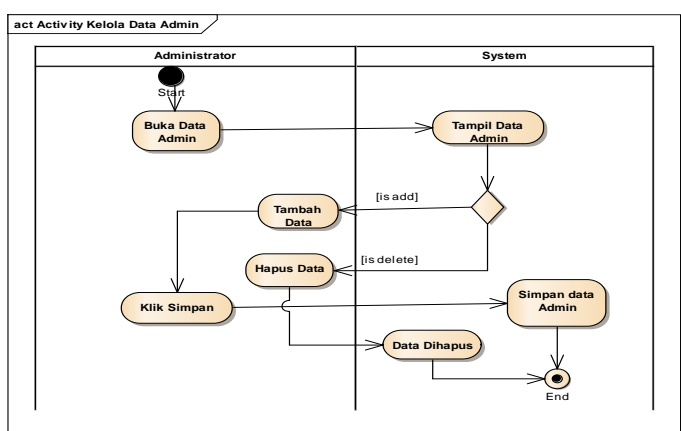

\section{Gambar 5. Activity Diagram Kelola Data Administrator}

Setelah administrator melakukan login system dan membuka data admin, maka akan tampil data administrator secara keseluruhan, dimana administrator dapat melakukan tambah data dan hapus data administrator lain.

\section{Activity Diagram Kelola Data Staff}

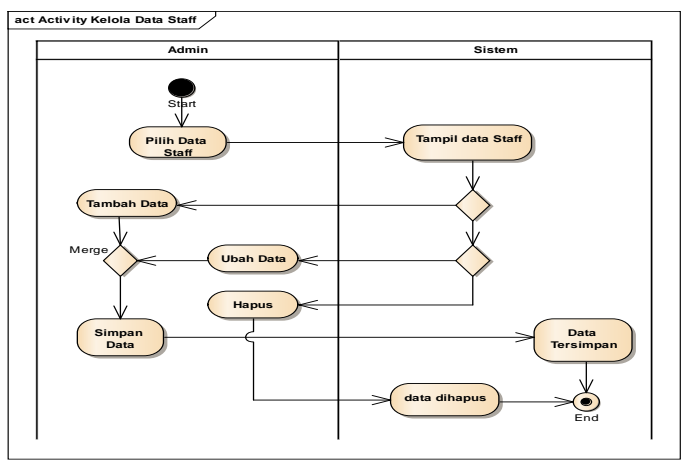

Gambar 6. Activity Diagram Kelola Data Staff

Setelah administrator melakukan login system dan membuka data staff, maka akan tampil data administrator secara keseluruhan, dimana administrator dapat melakukan tambah data dan hapus data staff yang akan dilakukan penilaian. 
3. Activity Diagram Kelola Data Supervisor

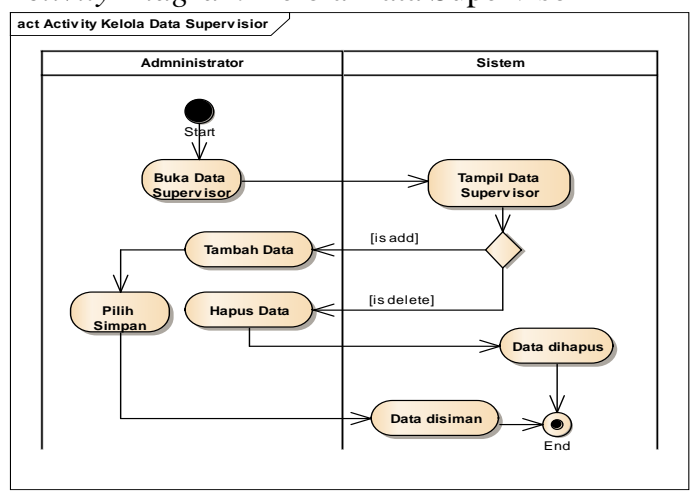

\section{Gambar 7. Activity Diagram Kelola Data Supervisor}

Setelah administrator melakukan login system dan membuka data supervisor, maka akan tampil data administrator secara keseluruhan, dimana administrator dapat melakukan tambah data dan hapus data supervisor yang dapat melakukan penilaian.

4. Activity Diagram Kelola Data Staff Penilai

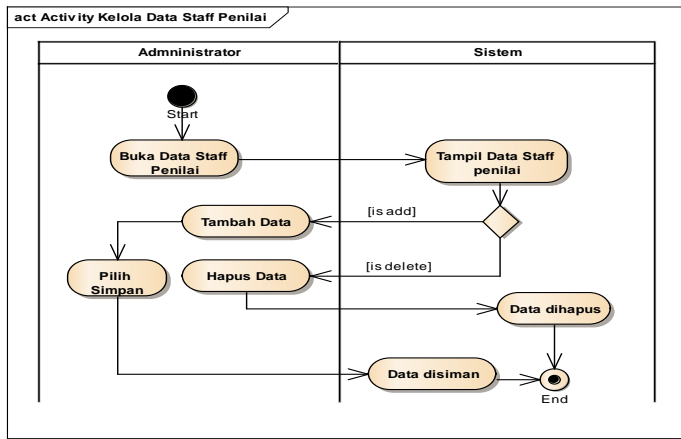

\section{Gambar 8. Activity Diagram Kelola Data Staff Penilai}

Setelah administrator melakukan login system dan membuka data staff penilai, maka akan tampil data administrator secara keseluruhan, dimana administrator dapat melakukan tambah data dan hapus data staff penilai yang dapat login kek sytem dan melakukan penilaian terhadap rekan sejawat.
5. Activity Diagram Kelola Data Posisi

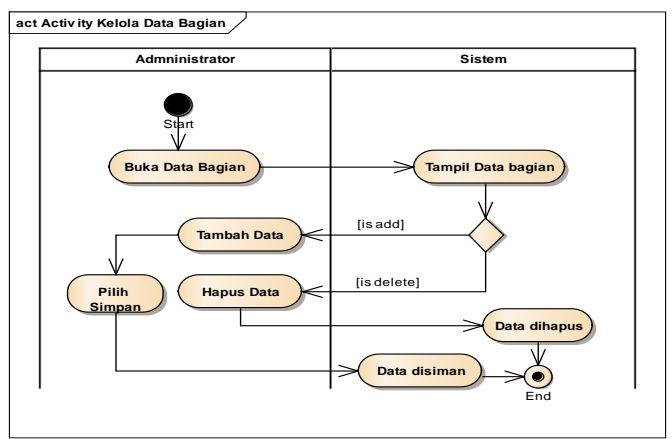

Gambar 9. Activity Diagram Kelola Data Posisi

Setelah administrator melakukan login system dan membuka data posisi, maka akan tampil data administrator secara keseluruhan, dimana administrator dapat melakukan tambah data dan hapus data posisi.

6. Activity Diagram Kelola Data Lokasi Kantor

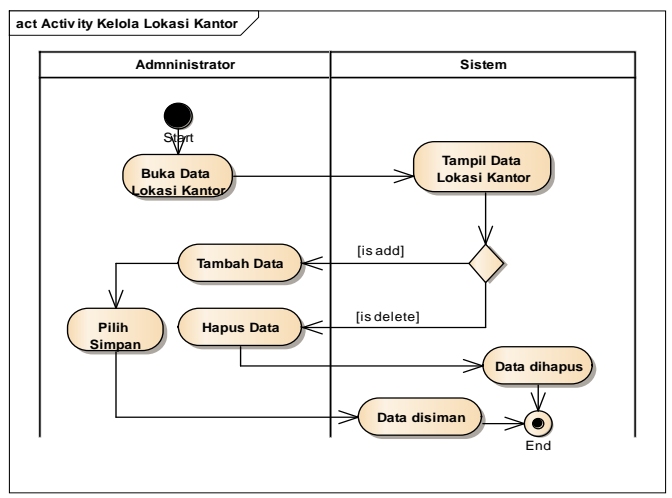

\section{Gambar 10. Activity Diagram Kelola Data Lokasi Kantor}

Setelah administrator melakukan login system dan membuka data lokasi kantor, maka akan tampil data administrator secara keseluruhan, dimana administrator dapat melakukan tambah data dan hapus data lokasi kantor cabang. 
7. Activity Diagram Kelola Periode Penilaian

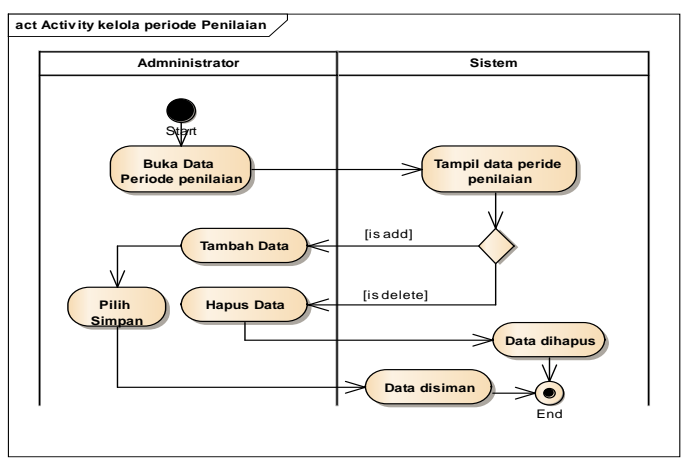

Gambar 11. Activity Diagram Kelola Data Periode Penilaian

Setelah administrator melakukan login system dan membuka data periode, maka akan tampil data administrator secara keseluruhan, dimana administrator dapat melakukan tambah data dan hapus data periode penilaian.

b. Activity Diagram Halaman Staff Penilai

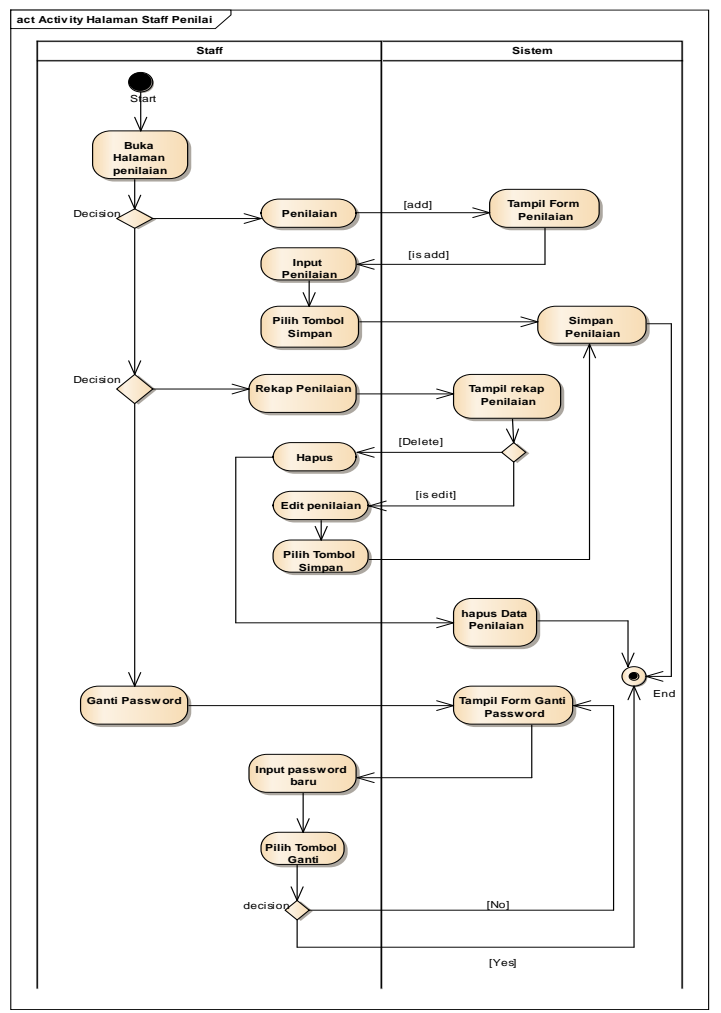

\section{Gambar 12. Activity Diagram Halaman Staff penilai}

Setelah staff penilai melakukan login kek system, dan membuka halaman penilaian, maka staff penilai dapat melakukan penilaian rekan sejawat, melihat dan mengelola rekap penilaian yang telah di berikan kepada rekan sejawat, jika ada penilaian yang perlu di revisi, staff penilaian dapat melakukan edit data.

8. Activity Diagram Laporan Penilaian

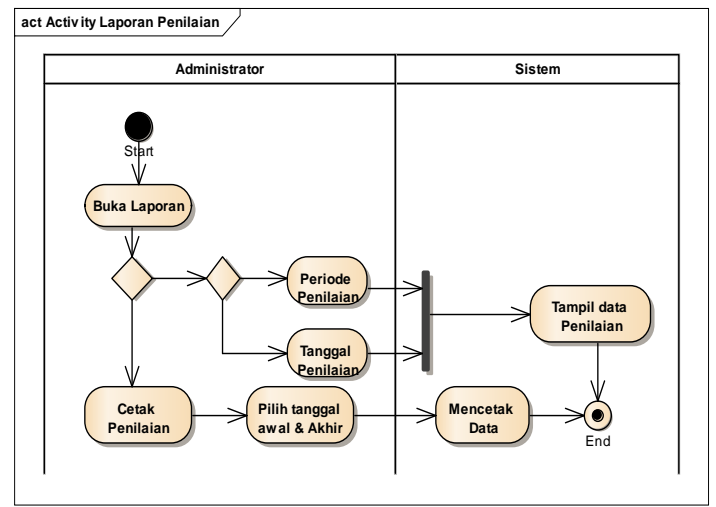

Gambar 13. Activity Diagram Laporan Penilaian

Untuk dapat melihat laporan penilaian user dapat memilih periode penilaian atau dengan memilih tanggal penilaian, selain itu juga user dapat mencetak hasil laporan penilaian.

c. Activity Diagram Halaman Supervisor 


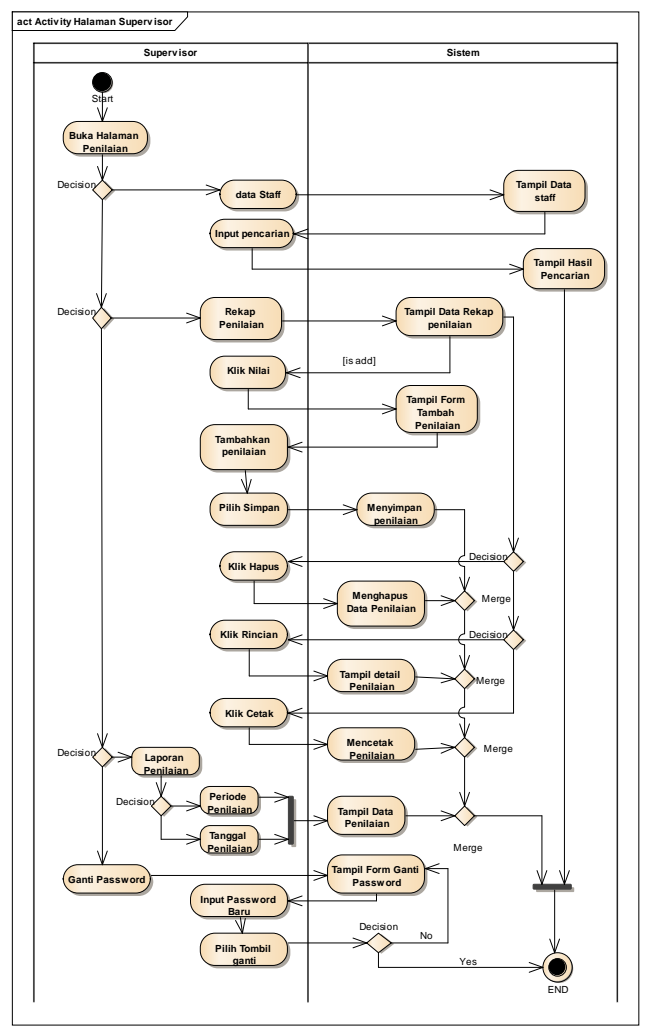

Gambar 14. Activity Diagram Penilaian Oleh Supervisor

Pada halaman supervisor, supervisor dapat melihat data staff, melihat laporan dan melakukan penilaian yang telah dilakukan penilaian sebelmnya oleh staff penilai, sehinga mendpatkan nilai akhir dari penilaian periode tersebut.

\subsection{Implementasi Sistem}

Pada tahap implementasi sistem merupakan suatu tahap dimana sistem informasi dapat dipakai sebagaimana tujuan yang diharapkan. Terdapat beberapa tahap aktivitas yang di lakukan, mulai dari rencana implementasi, kegiatan implementasi sampai tindak lanjut implementasi.

Agar implementasi berjalan dengan baik dan sesuai dengan apa yang diharapkan, maka suatu susunan rencana implementasi harus disusun dengan baik. Rencana dimaksudkan untuk mengukur besaran waktu, biaya dan resiko yang akan terjadi ketika implementasi berlangsung.

Dari perancangan sistem yang telah di buat, maka di peroleh tampilan yang meliputi form input, proses dan output.

\section{Form Login}

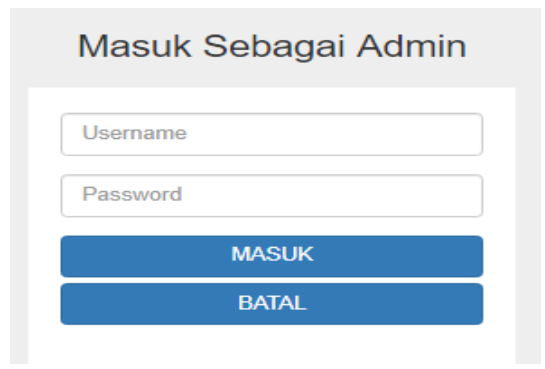

Gambar 15. Tampilan Login Administrator

Sebelum melakukan explore data dan melakukan penilaian, user harus melakukan login dengan memasukan username dan password yang benar.

2. Form Penilaian Oleh Staff Penilai.

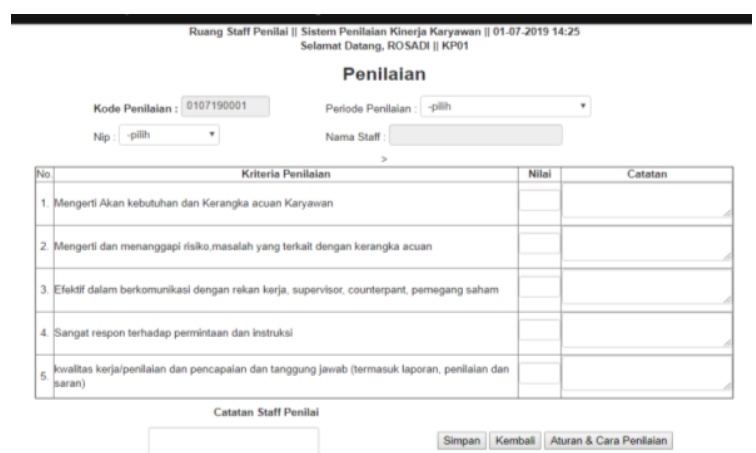

\section{Gambar 16. Tampilan Form Penilaian Oleh Staff penilai}

Form di atas, merupakan form untuk penginput penilaian yang dilakukan oleh staff penilai. Yang sebelumnya di lakukan menggunkan kertas dan dilakukan perhitungan rating secara manual, selanjutnya hasil peniaian tersebut akan langsng masuk ke halaman supervisor untuk dilakukan penilaian oleh supervisor, tanpa menunggu karyawan penilai selesai melakukan penilaian terhadap karyawan yang akan dinilai.

3. Form Penilain Oleh Supervisor

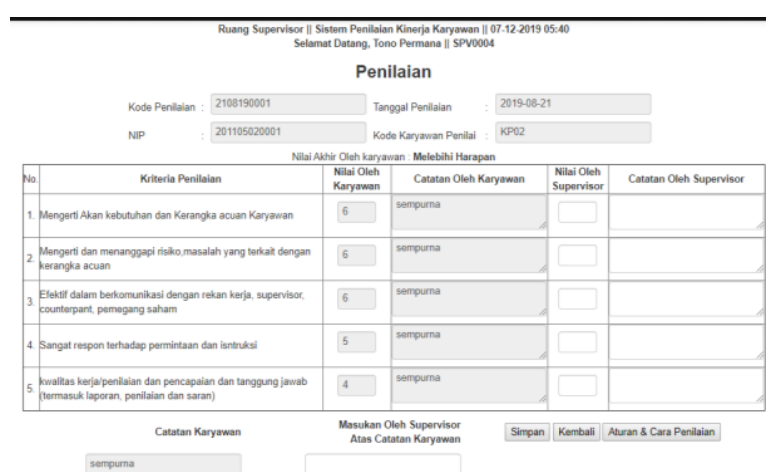

Gambar 17. Tampilan Form Penilaian Oleh Supervisor. 
Setelah staff penilaian melakukan penilaian, dan megklik simpan, otomatis data tersbut langsung dapat di akses oleh supervisor dan supervisor dapat langsung melakukan penilaian dengan mempertimbangkan nilai yang dimasukan oleh staff penilai, tanpa harus menunggu staff penilai menyerahkan form yang di isi menggunakan kertas.

\section{Hasil Akhir Penilaian}

Setelah dilakukan penilaian oleh staff penilai dan supervisor, maka akan dihasilkan nilai akhir, sebagai pertimbangan supervisor dalam mempertahankan kontrak kerja maupun promosi jabatan karyawan tersebu.

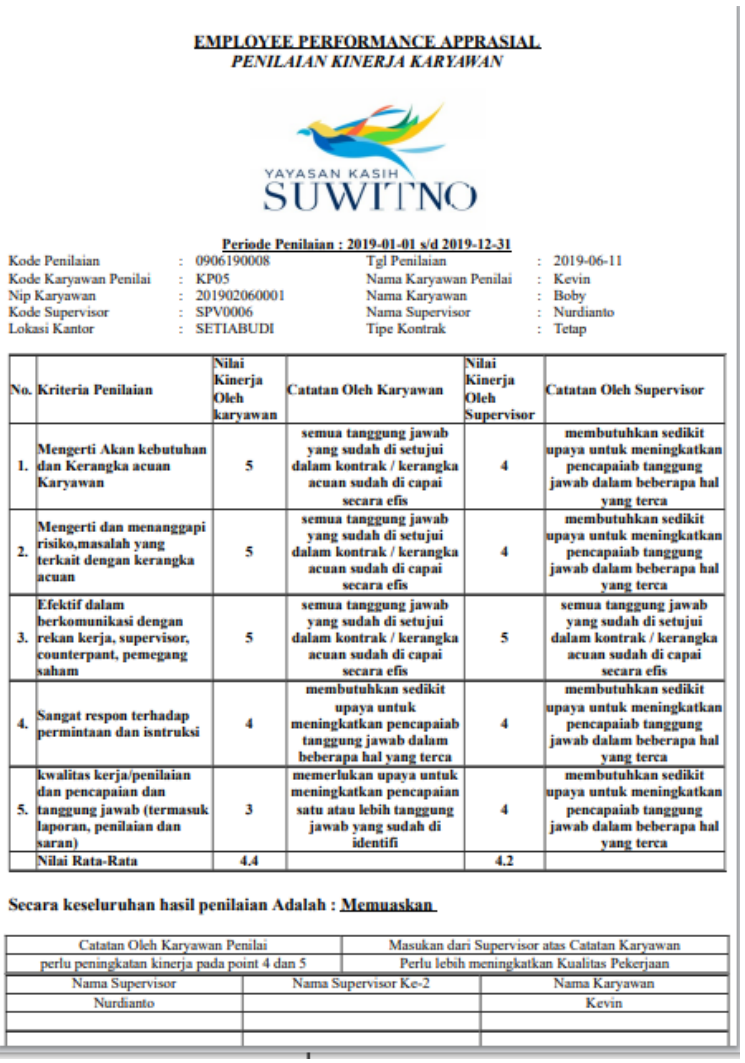

Gambar 18. Hasil Akhir Penilaian

5. Form Untuk menampilkan Laporan

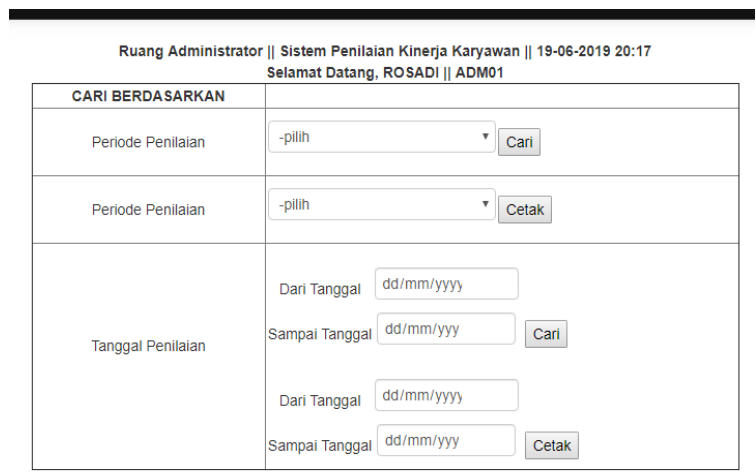

Gambar 19. Tampilan Form Laporan Penilaian

Dengan disimpannya penilaian kinerja karyawan dengan menggunakan sistem database, maka akan mempermudah supervisor dalam melihat hasil penilaian dalam setiap periode, tanpa harus membuka arsip penilaian yang sebelumnya masih dalam bentuk kertas atau hard copy. Hanya dengan memilih tanggal penilaian atau periode penilaian, supervisor dapat melihat data penilaian kinerja karyawan periode yang sudah pernah dilakukan penilaian.

6. Tampilan Laporan Penilaian.

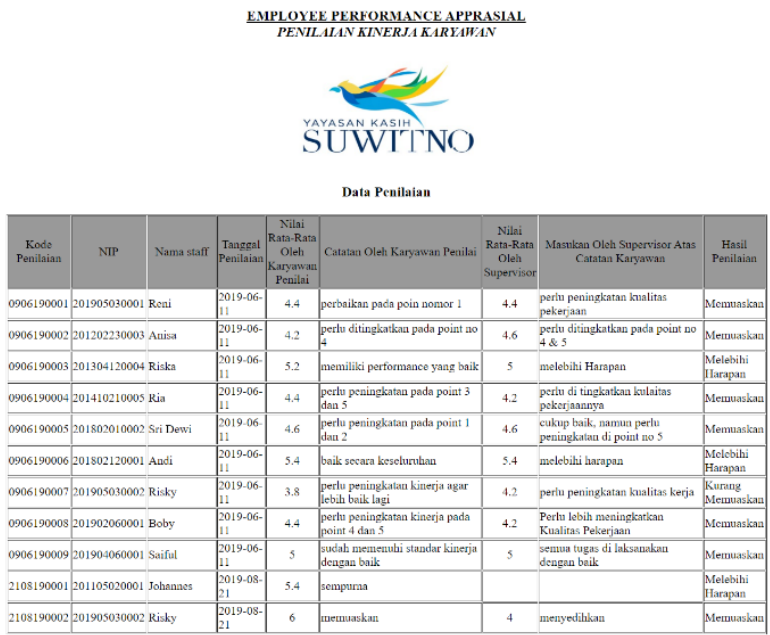

Gambar 20. Laporan Periode Penilaian 2019.

\section{Simpulan}

Dari hasil pengamatan dan perancangan sistem penilaian kinerja karyawan pada Yayasan Kasih Suwitno, maka penulis dapat menarik beberapa kesimpulan diantaranya sebagai berikut :

1. Sistem penilaian kinerja karyawan pada yayasan kasih suwitno masih menggunakan cara tradisional, dimana penilaian dilakukan dalam 
form kertas. Hal tersebut dapat merepotkan dalam proses perhitungan nilai rata-rata penilaian.

2. Pada sistem penilaian kinerja karyawan yang di lakukan secara tradisional, penyimpanan arsip data hasil penilaian kinerja karyawan juga memerlukan ruang yang cukup besar, sehingga menyulitkan dalam proses penyimpanan data hasil penilaian.

3. Dengan adanya aplikasi sistem penilaian kinerja karyawan berbasis web, maka mempermudah penilaian dan dapat melihat hasil penilaian secara langsung setelah selesai melakukan penilaian.

4. Sistem informasi penilaian kinerja karyawan merupakan aplikasi sistem yang terkomputerisasi yang dibuat berbasis web dengan database dan terpusat, penyimpanan hasil penilaian juga dalam bentuk digital, selain mengurangi ruang penyimpanan hasil penilaian, juga mempermudah dalam pengelolaan data dan laporannya.

5. Karena sistem yang terintegrasi, maka pihak pusat atau supervisor, dapat lebih cepat menerima hasil penilaian oleh staff penilai, sehingga akan mempermudah dalam proses penilaian oleh supervisor.

6. Hasil penilaian kinerja karyawan tersimpan dalam bentuk data digital yang terintegrasi, sehingga mempermudah dalam melihat hasil penilan kinerja karyawan setiap periode penilaian, yang bertujuan untuk melihat perkembangan kinerja karyawan yang ada di Yayasan Kasih Suwitno untuk selanjutnya sebagai bahan pertimbangan perpanjang kontrak maupun promosi jabatan.

\section{Referensi}

A.S, R., \& M.salahuddin. (2018). Rekayasa Perangkat Lunak terstruktur dan Berorientasi Objek. Bandung: Informatika.

Agung, D., Sulistiowati, R., Lemantara, J., Vol, J., \& Tahun, N. (2016). ISSN 2338-137X Rancang Bangun Aplikasi Penilaian Kinerja Pegawai
Berdasarkan Metode Graphic Rating Scale Pada Rumah Sakit PHC Surabaya ISSN 2338-137X, 06(7), 1-7.

Aldo, D., \& Informasi, S. (2019). SATIN - Sains dan Teknologi Informasi Sistem Pakar Diagnosa Penyakit Limfoma dengan Metode Certainty Factor, 5(1).

Andini, S., \& Arif, M. F. (2017). Rancang Bangun Sistem Informasi Pusat Pelatihan Dan Penilaian Kinerja Karyawan Pada Sentra Pendidikan Bank Rakyat Indonesia (Bri) Padang BeRBASIS WEB ISSN:2086-4981, 10(1), 40-52.

Efrando, A. (2019). SATIN - Sains dan Teknologi Informasi Monitoring pada Server STMIK Amik Riau dengan Menggunakan Suricata Melalui Notifikasi Bot Telegram, 5(1).

Hamali, A. Y. (2018). Pemahaman Manajemen Sumber Daya Manusia. (B. Seda, Ed.) (Catakan Ke). Jakarta: PT. Buku Seru.

Kurniawan, J. A., Sulistiowati, \& Mastan, I. A. (2016). Rancang Bangun Aplikasi Penilaian Kinerja Pegawai Berbasis Web Menggunakan Metode Scoring System Pada Badan Kepegawaian Daerah Provinsi Jawa Timur Issn 2338-137X, 5(5), 1-8.

Magai, A., Winarno, W. W., Nasiri, A., Ring, J., Utara, R., Catur, C., ... Indonesia, Y. (2018). Analisis Efisiensi Sistem Informasi Kinerja Pegawai Berbasis Komputer Pada Dinas Pariwisata Di Kabupaten Sleman Yogyakarta, XIII(November), 24-33.

Munawar. (2018). Analisis Perancangan Sistem Berorientasi Objek dengan UML. Bandung: Informatika.

Safitri, K., \& Waruwu, F. T. (2017). Berprestasi Dengan Menggunakan Metode Analytical Hieararchy Process ( Studi Kasus : PT . Capella Dinamik Nusantara Takengon ), 1(1), 17-21. 